\title{
BMJ Open Comparing sutures versus staples for skin closure after orthopaedic surgery: systematic review and meta-analysis
}

\author{
Rohin Krishnan, S Danielle MacNeil, Monali S Malvankar-Mehta
}

To cite: Krishnan $\mathrm{R}$, MacNeil SD, MalvankarMehta MS. Comparing sutures versus staples for skin closure after orthopaedic surgery: systematic review and meta-analysis. BMJ Open 2016:6:e009257.

doi:10.1136/bmjopen-2015009257

- Prepublication history and additional material is available. To view please visit the journal (http://dx.doi.org/ 10.1136/bmjopen-2015009257)

Received 29 June 2015 Revised 22 September 2015 Accepted 23 October 2015

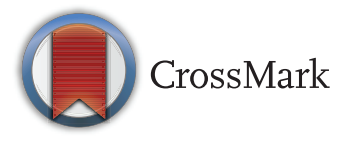

Department of Epidemiology and Biostatistics, Western University, London, Ontario, Canada

\section{Correspondence to}

Rohin Krishnan;

rkrishn6@uwo.ca

\section{ABSTRACT}

Objective: To determine whether there still remains a significant advantage in the use of sutures to staples for orthopaedic skin closure in adult patients.

Design: Systematic Review/ Meta-Analysis.

Data sources: MEDLINE-OVID, EMBASE-OVID, CINAHL and Cochrane Library. Grey and unpublished literature was also explored by searching: International Clinical Trial Registry, Grey Matters BIOSIS Previews, Networked Digital Library of Theses and Dissertations, ClinicalTrials.gov, UK Clinical Trials Gateway, UK Clinical Research Network Study Portfolio, Open Grey, Grey Literature Report, and Web of Science.

Selection criteria: Articles were from any country, written in English and published after 1950. We included all randomised control trials and observational studies comparing adults ( $\geq 18$ years) undergoing orthopaedic surgery who either received staples or sutures for skin closure. The primary outcome was the incidence of surgical site infection. Secondary outcomes included closure time, inflammation, length of stay, pain, abscess formation, necrosis, discharge, wound dehiscence, allergic reaction and health-related quality of life.

Results: 13 studies were included in our cumulative meta-analysis conducted using Review Manager V.5.0. The risk ratio was computed as a measure of the treatment effect taking into account heterogeneity. Random-effect models were applied. There was no significant difference in infection comparing sutures to staples. The cumulative relative risk was 1.06 (0.46 to 2.44). In addition, there was no difference in infection comparing sutures to staples in hip and knee surgery, respectively. Lastly, except for closure time, there was no significant difference in secondary outcomes comparing sutures to staples.

Conclusions: Except for closure time, there was no significant difference in superficial infection and secondary outcomes comparing sutures to staples was found. Given that there may in fact be no difference in effect between the two skin closure and the methodological limitations of included studies, authors should begin to consider the economic and logistic implications of using staples or sutures for skin closure. PROSPERO registration number: CRD42015017481.

\section{INTRODUCTION}

In the context of orthopaedic surgery, surgical site infection (SSI)-defined as the
Strengths and limitations of this study

Systematic review and meta-analysis (SRMA) completed with high methodological rigour.

- Compared with a previous SRMA, we found no significant difference comparing sutures to staples across all outcomes and subgroups.

- Poor quality of evidence, and significant heterogeneity in effect across included studies.

- Owing to lack of data, our SRMA did not capture the effect of suture material and/or surgeon skill, which could be a potential unmeasured confounder.

occurrence of wound infection following surgery $^{1}{ }^{2}$-are frequent postoperative complications that represent $20 \%$ of all nosocomial infections. SSIs are clinically classified as the occurrence of infection affecting either the superficial or deep incision sites within 30 days postoperatively or within 1 year if an implant is left inside the patient. ${ }^{1}$ Orthopaedic SSIs are frequent postoperative complications that represent $20 \%$ of all nosocomial infections. In addition, orthopaedic SSIs have been shown to extend postoperative hospital stay, double hospital readmission rates and increase annual healthcare costs up to $300 \%{ }^{1-4}$ Unfortunately, orthopaedic SSIs also inflict a tremendous burden on the patient, often increasing physical limitations and reducing postoperative quality of life. ${ }^{45}$

In response to the critical need to reduce the incidence of SSIs, a wealth of research has been published identifying effective preoperative, intraoperative and postoperative strategies to reduce the incidence of SSIs. ${ }^{1}$ Preoperative strategies include increasing host immune status, prophylactic antibiotic administration and proper sterilisation of the patient and all surgical staff. ${ }^{6}$ During surgery, it is imperative that the surgical environment is properly ventilated, all surgical equipment are sterilised, and the use of proper surgical technique is employed. ${ }^{6}$ Postoperatively, 
incisions should be properly wrapped with sterile dressing and proper sterile techniques should be used during dressing changeover. ${ }^{6}$

With the increased pressure on orthopaedic surgeons to promote rapid wound healing, reduce postoperative length of stay (LOS) and complications, the method of skin closure during surgery has become increasingly important. ${ }^{7-9}$ The optimal goal of skin closure, is to promote rapid skin healing and an acceptable cosmetic result while minimising the risk of dehiscence or infection'. ${ }^{7}$ In orthopaedic surgery, the most common skin closure methods are the use of staples or sutures. ${ }^{7} 1011$ Yet, there seems to be no consensus in the literature as to which closure method is superior, with some studies reporting no difference and others reporting a higher wound complication rate following the use of staples. ${ }^{9} 12-15$

A systematic review and meta-analysis (SRMA), published in 2009, compared the efficacy of sutures to staples after orthopaedic surgery. ${ }^{7}$ They reported that the risk for postoperative infection was over three times greater in patients who receive staples for skin closure as compared with those who receive sutures. ${ }^{7}$ Yet, due to small sample sizes, noticeable heterogeneity in effect size across outcomes, and lack of methodological rigour within studies, called for additional research in this area. $^{7-10} 12$ 15-17

Consequently, in response to the paucity of information and continuing discrepancy of results, numerous observational studies and RCTs have been published within the past 6 years comparing methods of skin closure after orthopaedic surgery. Therefore, the primary aim of our study is to perform an updated SRMA, and to investigate whether there still remains an advantage in the use of sutures to staples for orthopaedic skin closure.

\section{METHODS}

\section{Search strategy}

We searched MEDLINE-OVID, EMBASE-OVID, CINAHL and Cochrane Library from 1950 to January 2015 (see online supplementary appendix A for detailed search strategy pertaining to each databases). Grey and unpublished literature was also explored by searching: International Clinical Trial Registry, Grey Matters, BIOSIS Previews, Networked Digital Library of Theses and Dissertations, ClinicalTrials.gov, UK Clinical Trials Gateway, UK Clinical Research Network Study Portfolio, Open Grey, Grey Literature Report, and Web of Science. The following databases were searched within the Web of Science platform: Web of Science Core Collection, BIOSIS Previews, KCI-Korean Journal Database, MEDLINE, SciELO Citation Index, and Zoological Record. Conference Proceedings were indexed within the Web of Science Core Collection database search. No language or date of coverage restrictions was placed on all searches. Lastly, on completion of levels 1, 2 and 3 screening, forward and backward citation searches were done to assure no studies were mistakenly omitted from our search strategy. A review protocol was submitted and approved with PROSPERO on 10 March 2015, and approved on 12 March 2015 (registration number: CRD42015017481). The search strategy was designed to accommodate for database and platform-specific terminology, and syntax. A detailed search strategy including MeSH terms, keywords and Boolean operators can be found within the online supplementary appendix.

\section{Population, Intervention, Comparator, Outcomes and Study Design}

The Population, Intervention, Comparator, Outcomes and Study Design (PICOS) were adopted from Smith et $a l^{7}$ Articles were from any country, written in English and published after 1950. We included all randomised control trials and observational studies (not an editorial, opinion, case report or a review article) comparing adults ( $\geq 18$ years) undergoing orthopaedic surgery (trauma or elective) who either received staples or sutures (excluding skin adhesives, barbed sutures and surgical zipper) for skin closure. The primary outcome was the incidence of SSI after orthopaedic surgery. Secondary outcomes included closure time, inflammation, LOS, patient satisfaction, pain, abscess formation, necrosis, discharge, wound dehiscence, allergic reaction and health-related quality of life (HRQoL). This study has been reported according to the PRISMA guidelines. $^{18}$

\section{Study selection}

A total of 947 studies were identified and imported into EPPI V.4.0 Reference Manager. As per the prespecified search strategy, 280 studies were retrieved through relevant database searches and an additional 667 studies retrieved from grey literature searches and various clinical trial registries. After removing 216 duplicates, 731 articles underwent title screening. Studies were excluded if they were not, human $(n=4)$, not a research study $(n=11)$, and if they did not look at orthopaedic surgery $(n=84)$ or skin closure $(n=511)$. On completion of level 1 screening, 610 studies were excluded and 121 were included for level 2 (abstract) screening. Studies were excluded if they did not directly compare sutures to staples for skin closure $(n=102)$. Nineteen studies were eligible for full-text screening. Articles were excluded if: they were not English $(n=1)$, the results were not published $(n=1)$, the studies had not yet completed ( $\mathrm{n}=2$; International Clinical Trial Registry: (1) TCTR20140312001 and (2) NTR3946) and if one could not differentiate results from orthopaedic and nonorthopaedic groups $(n=1)$. Contact with authors were attempted to obtain English manuscripts, and any unpublished results or interim data. Two independent reviewers (RK and SDM) assessed articles for eligibility; $\kappa$ statistics were calculated to assess reviewer agreement on the completion of levels 1 and 2 screening. 
Additionally, all disagreements were corrected through negotiated consensus. The agreement between reviewers for levels 1 and 2 screening was: 0.50 and 0.85 , respectively. A detailed PRISMA flow chart outlining the number of studies screened for eligibility, and reasons for exclusion are provided in figure 1. Specific screening questions are provided in the online supplementary appendix.

\section{Data extraction}

Relevant quantitative and qualitative data necessary for adequate study comparison and analysis was abstracted by a reviewer (RK). Information on study objective, design, operation type, closure material, sample size, age (mean), sex ratio, time to removal, follow-up, infection, closure time, inflammation, LOS, patient satisfaction, pain, abscess formation, necrosis, discharge, wound dehiscence, allergic reaction and HRQoL was collected. All outcomes were prespecified within PROSPERO.

\section{Risk of bias assessment}

Studies were critically appraised for adequate randomisation, allocation concealment, baseline similarity, blinding, follow-up completion and intention-to-treat (ITT) analysis. Subsequently, using the Grading of Recommendations, Assessment, Development, and Evaluation (GRADE) guidelines, included articles were used to assign an overall grade of either high, moderate, low quality of evidence for infection. ${ }^{19-22}$

\section{Summary measures and statistical analysis}

Statistical analysis was conducted using Review Manager V.5.0. ${ }^{23}$ Dichotomous outcomes were reported as risk ratios and continuous outcomes as mean differences (MDs). All analyses were conducted using the Mantel-Haeszel random-effects model. Heterogeneity was assessed using the $\chi^{2}$ and $\mathrm{I}^{2}$. All results were reported at a significance level of 0.05 , and $95 \%$ CI was provided. Stratification of infection based on surgery type has been prespecified, and a funnel plot was calculated to assess publication bias. In addition, ITT analysis was performed in studies in which results were reported 'as per protocol'. Subsequently, sensitivity analysis was performed, accounting for studies in which there was lost to follow-up.

\section{RESULTS}

\section{Study selection}

Thirteen studies were included in our cumulative meta-analysis (table 1)..$^{8-10} 12$ 15-17 24-29 All articles were published between 1990 and 2015. The cumulative sample size of all studies was 563 patients within the suture group, and 692 patients within the staple group. Ten studies were randomised controlled trials and three were observational studies. ${ }^{82629}$
Figure 1 PRISMA flow diagram. $^{33}$

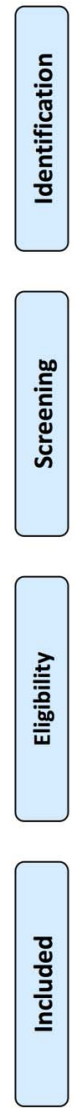

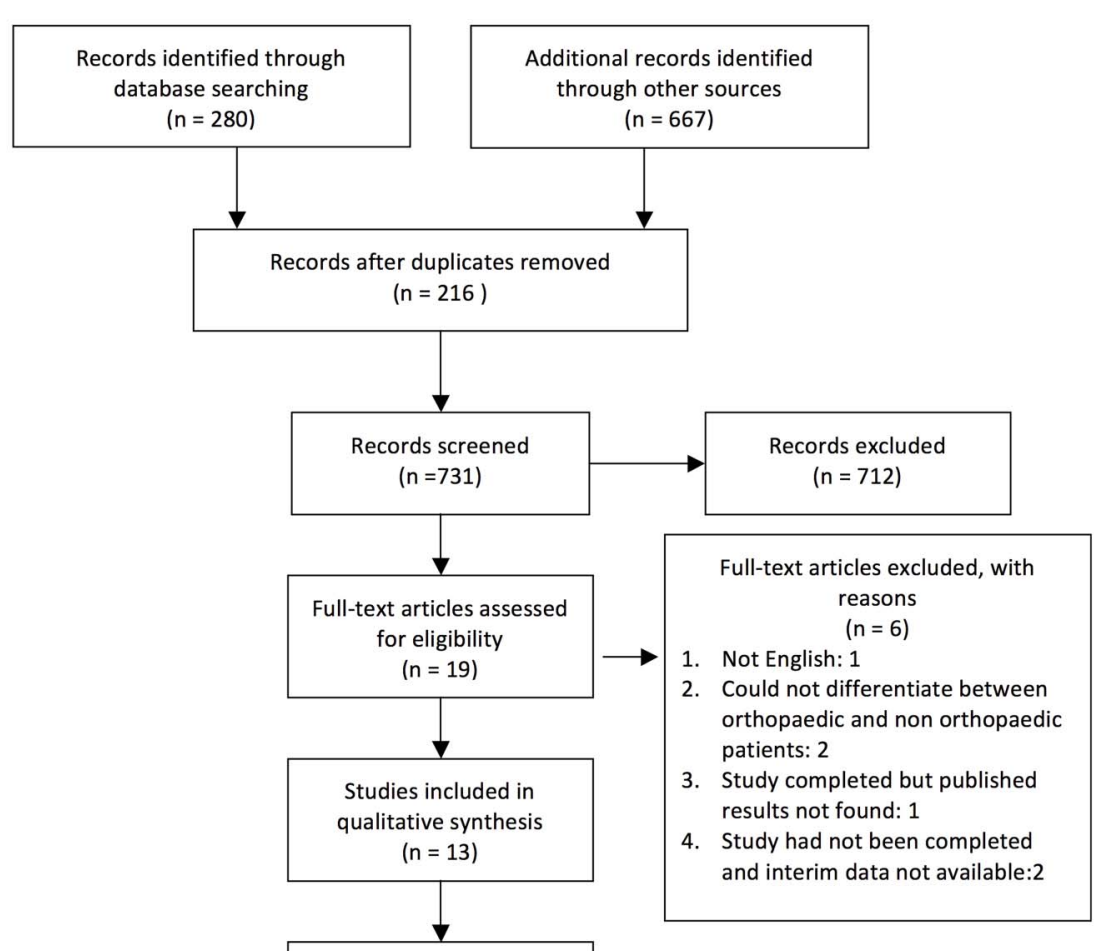

Studies included in quantitative synthesis (meta-analysis) $(n=13)$ 
Table 1 Baseline characteristics

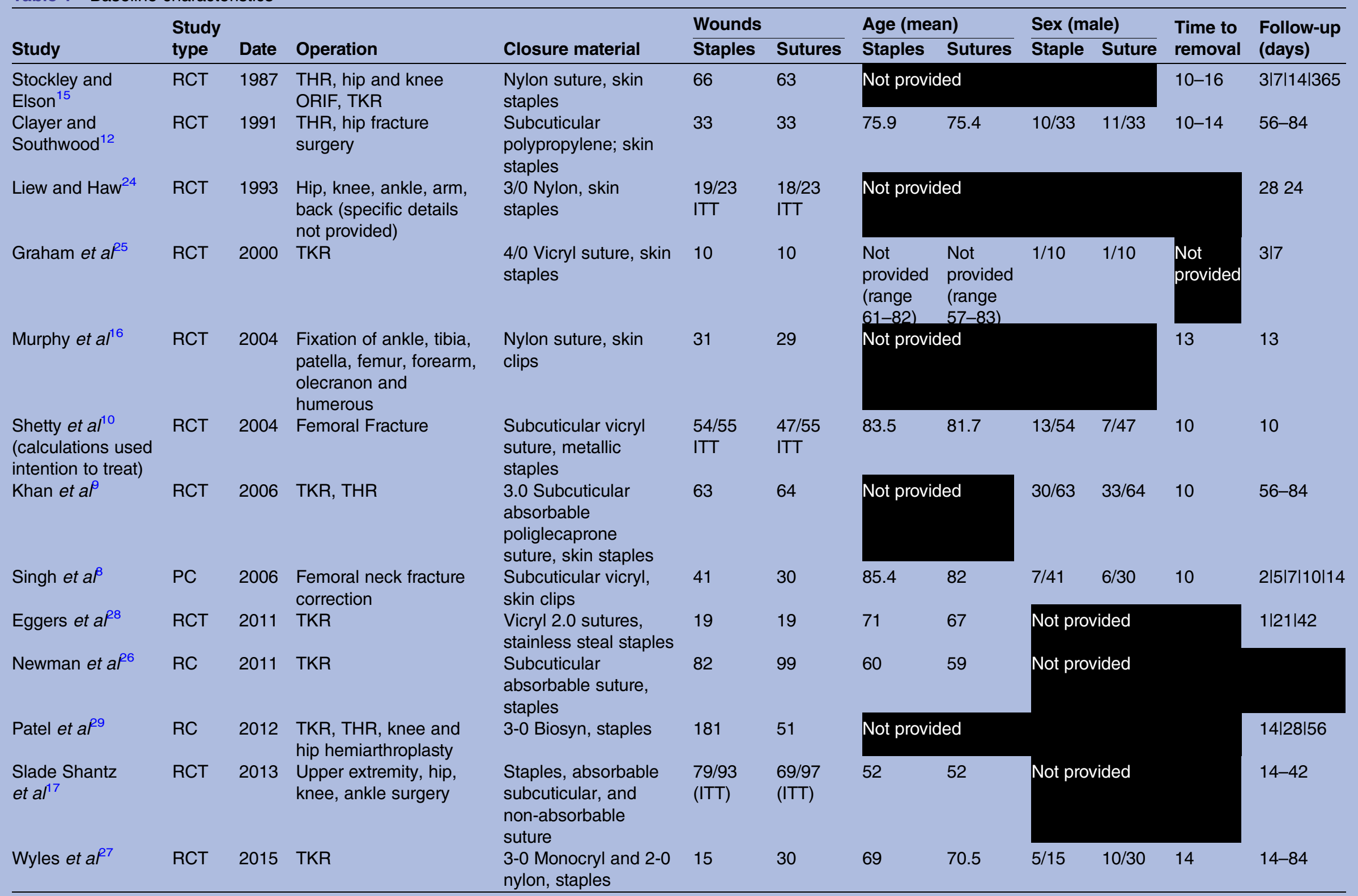

Baseline characteristics of all included studies. All missing information are omitted in black.

ITT: sample size when considering intention to treat.

ORIF, fraction open reduction, internal fixation; PC, prospective cohort; RC, retrospective cohort; RCT, randomised controlled trial; THR, total hip arthroplasty; TKR, total knee arthroplasty. 


\section{Study characteristics}

Seven studies provided data on the mean age of patients within each group. ${ }^{8} 10 \quad 12 \quad 17 \quad 26-28$ Using sample size weights, the overall mean age among the staple and suture groups were 68 and 66 years, respectively. Six studies provided data on the distribution of sex within each group. ${ }^{8-10} 122527$ Among the 216 patients who received staples, there were 66 males and 150 females. Additionally, among the 214 patients within the suture group, there were 68 males and 146 females. The majority of studies focused on lower extremity orthopaedic operations. Surgeries ranged from total knee arthroplasty; total hip arthroplasty; hip fracture surgery; knee fracture surgery; and miscellaneous ankle, tibia, patella, olecranon and humerus fracture corrections. Of the seven articles that included more than one surgery type, only three studies stratified the results based on procedure. $^{9} \quad 15{ }^{29}$ Six studies did not report suture and staple removal time. ${ }^{17} 24-262829$ In the 12 papers that provided the relevant data, the overall time to removal was consistent across all studies and ranged from 10 to 16 days. One study did not report suture and staple follow-up time. ${ }^{26}$ Among the rest, there was considerable variation in postoperative follow-up, ranging from 3 to 365 days.
There was some variation in suture material. The most common materials used were Nylon and Vicryl. A summary of all baseline characteristics abstracted from included studies can be found in table 1 .

\section{Risk of bias assessment}

A risk of bias assessment of all 13 studies showed considerable variation in study quality (table 2). Two studies were retrospective chart reviews, ${ }^{26}{ }^{29} 1$ study was a prospective cohort $^{8}$ and 10 studies were randomised controlled trials. ${ }^{9} 101215-1724252728$ Of the 10 RCTs, 2 study did not appropriately randomise patients, ${ }^{12} 15$ 5 studies did not perform or clearly report allocation concealment, ${ }^{12} 15162425$ and 5 studies did not provide baseline characteristics ${ }^{10} 15162425$ In addition, seven studies did not blind patients ${ }^{10} 12 \quad \begin{array}{llllll}15 & 16 & 24 & 25 & 27 & \text { and six }\end{array}$ studies did not perform or did not clearly report ITT analysis. ${ }^{10} 1617242528$ However, among all included articles, only six did not complete or adequately report follow-up. ${ }^{15-17} 2425{ }^{29}$ Despite the low quality, all studies were included in the analysis. Lastly, with respect to our primary outcome of infection, an overall grade of 'very low quality' was assigned due to the considerable

Table 2 Critical appraisal of included studies

\begin{tabular}{|c|c|c|c|}
\hline \multicolumn{4}{|c|}{ Were the patients similar at the start? } \\
\hline Study & Randomisation & Allocation concealed & Baseline characteristics similar \\
\hline Stockley and Elson ${ }^{15}$ & $x$ & $X$ & $?$ \\
\hline Clayer and Southwood ${ }^{12}$ & $\mathrm{X}$ & $\mathrm{X}$ & $\checkmark$ \\
\hline Liew and $\mathrm{Haw}^{24}$ & $\checkmark$ & $?$ & $?$ \\
\hline Graham et al 25 & $\checkmark$ & $?$ & $?$ \\
\hline Murphy et $a l^{16}$ & $\checkmark$ & $?$ & $?$ \\
\hline Shetty et al ${ }^{10}$ & $\checkmark$ & $\checkmark$ & $?$ \\
\hline Khan et aP & $\checkmark$ & $\checkmark$ & $\checkmark$ \\
\hline Singh et $a \beta^{\beta}$ & $\mathrm{x}$ & $\mathrm{X}$ & $\checkmark$ \\
\hline Eggers et $a{ }^{28}$ & $\checkmark$ & $\checkmark$ & $\checkmark$ \\
\hline Newman et af6 & $x$ & $\mathrm{X}$ & $?$ \\
\hline Patel et $a{ }^{29}$ & $\mathrm{x}$ & $x$ & $?$ \\
\hline Slade Shantz et al ${ }^{17}$ & $\checkmark$ & $\checkmark$ & $\checkmark$ \\
\hline Wyles et $a f^{27}$ & $\checkmark$ & $\checkmark$ & $\checkmark$ \\
\hline \multicolumn{4}{|c|}{ Were the patients similar throughout? } \\
\hline Study & Blinding & Follow-up complete & Intention-to-treat analysis \\
\hline Stockley and Elson ${ }^{15}$ & $\mathrm{X}$ & $?$ & $\checkmark$ \\
\hline Clayer and Southwood ${ }^{12}$ & $\mathrm{X}$ & $\checkmark$ & $\checkmark$ \\
\hline Liew and $\mathrm{Haw}^{24}$ & $\mathrm{X}$ & $\mathrm{X}$ & $?$ \\
\hline Graham et $a^{25}$ & $\mathrm{x}$ & $?$ & $?$ \\
\hline Murphy et $a l^{16}$ & $x$ & $x$ & $x$ \\
\hline Shetty et al ${ }^{10}$ & $\mathrm{x}$ & $\checkmark$ & $x$ \\
\hline Khan et al & $\checkmark$ & $\checkmark$ & $\checkmark$ \\
\hline Singh et $a^{\beta}$ & $x$ & $\checkmark$ & $x$ \\
\hline Eggers et $a{ }^{88}$ & $\checkmark$ & $\checkmark$ & $\checkmark$ \\
\hline Newman et $a^{26}$ & $x$ & $\checkmark$ & $x$ \\
\hline Patel et $a{ }^{29}$ & $x$ & $?$ & $x$ \\
\hline Slade Shantz et al ${ }^{17}$ & $\checkmark$ & $x$ & $x$ \\
\hline Wyles et $a^{p^{7}}$ & $x$ & $\checkmark$ & $\checkmark$ \\
\hline
\end{tabular}


Table 3 Grade assessment for overall quality of evidence with respect to infection

\begin{tabular}{|c|c|c|c|c|c|}
\hline $\begin{array}{l}\text { Number of participants } \\
\text { (studies) } \\
\text { Follow-up }\end{array}$ & Inconsistency & Indirectness & Imprecision & Publication bias & $\begin{array}{l}\text { Dverall } \\
\text { uality of } \\
\text { vidence }\end{array}$ \\
\hline \multicolumn{6}{|l|}{ Infection (follow-up: range 365 days) } \\
\hline $\begin{array}{ll}761 & \text { Serious }^{1-6} \\
(10 \mathrm{RCTs}) & \end{array}$ & Not serious $^{7}$ & Not serious $^{8}$ & Serious $^{9}$ & $\begin{array}{l}\text { Publication bias } \\
\text { strongly suspected }^{10}\end{array}$ & \\
\hline \multicolumn{6}{|l|}{ Infection (follow-up: range 365 to) } \\
\hline $\begin{array}{ll}484 & \text { Serious }^{1} \\
\text { (3 observational studies) } & \\
\end{array}$ & Serious $^{7}$ & Not serious $^{8}$ & Serious $^{9}$ & $\begin{array}{l}\text { Publication bias } \\
\text { strongly suspected }\end{array}$ & \\
\hline \multicolumn{6}{|c|}{$\begin{array}{l}\text { GRADE evaluation for overall quality of evidence. Included studies are separated into clinical trials and observational studies. Overall, } \\
\text { included studies are of very low quality. Explanations for risk of bias, inconsistency, indirectness, imprecision and publication bias are } \\
\text { provided below. } \\
\text { 1. Singh et al, }{ }^{8} \text { Newman et al, }{ }^{26} \text { Patel et a }{ }^{29} \text { were observational studies (no randomisation, allocation concealment, blinding). } \\
\text { 2. Clayer and Southwood and Stockley et al did not truly randomise (randomised based on unit number and date of birth). } \\
\text { 3. Of the randomised trials, six studies did not report or conceal allocation. } \\
\text { 4. Of the randomised trials, seven studies did not blind (patient or assessor) to the treatment (staples or sutures). } \\
\text { 5. For seven studies, completion of follow-up for all patients was not clearly reported or did not occur. } \\
\text { 6. For two studies infection was not the primary outcome. } \\
\text { 7. } I^{2} \text { value }<75 \% \text {. } \\
\text { 8. All studies included in the meta-analysis directly compare sutures to staples. } \\
\text { 9. Very few events occurred in suture and staple treatment arms resulting in very large confidence intervals. } \\
\text { 10. One study did not publish results and was excluded from our systematic review/ meta-analysis. } \\
\text { GRADE, Grading of Recommendations, Assessment, Development, and Evaluation; RCT, randomised controlled trial. }\end{array}$} \\
\hline
\end{tabular}

amount of imprecision, inconsistency and indirectness among the evidence (table 3).

\section{Primary outcome: infection}

All studies provided information on infection among patients receiving sutures and staples for skin closure (table 4). Wound infection comparing sutures to staples was insignificant, with a cumulative relative risk (RR) of 1.06 (95\% CI 0.45 to 2.44 ); figure 2 ).

\section{Secondary outcomes}

1. Dehiscence: Seven studies provided data on wound dehiscence. 8101216262829 The cumulative risk ratio was insignificant, with a RR of 0.96 (0.32 to 2.84; table 4 and figure 3 ).

2. Inflammation, discharge, necrosis, allergic reaction abscess formation: There was no significant difference in effect comparing sutures to staples across all of these outcomes (table 4 ).
3. Pain: Two studies measured pain. ${ }^{15} 17$ Slade Shantz et $a l^{17}$ assessed pain using the $100 \mathrm{~mm}$ pain scale, and Stockley and Elson ${ }^{15}$ noted 31 cases of reported pain among removal of staples as compared to seven cases of reported pain within the suture group. Although no inferential statistics was used, it seems that staples may be more painful to remove than sutures.

4. Closure time: Four studies provided information on closure time. ${ }^{9} \quad 17 \quad 24 \quad 28$ However, only within two studies was mean closure time provided or calculable. ${ }^{17}$ The cumulative MD was significant, with a MD of 5.84 (4.52 to 7.15) comparing suture and staple groups. Qualitatively, Liew and $\mathrm{Haw}^{24}$ noted that wound closure was approximately 7 times faster with staples compared with sutures. No inferential statistics was used. Lastly, Khan et a $f^{9}$ noted that closure time was faster using skin clips compared with sutures. Data were reported as the median and

Table 4 Primary and secondary outcomes comparing suture to staples for skin closure after orthopaedic surgery

\begin{tabular}{|c|c|c|c|c|c|c|}
\hline \multirow[b]{2}{*}{ Outcome } & \multicolumn{2}{|c|}{ Incidence } & \multirow[b]{2}{*}{ Relative risk $(95 \% \mathrm{Cl}$} & \multirow[b]{2}{*}{ p Value } & \multicolumn{2}{|c|}{ Heterogeneity } \\
\hline & Sutures & Staples & & & $I^{2}(\%)$ & $\chi^{2}$ (p Value) \\
\hline Infection $^{8-10} 12$ 15-17 24-29 & $17 \mid 563$ & 211692 & $1.06(0.46$ to 2.44$)$ & 0.89 & 18 & 0.27 \\
\hline Dehiscence $^{8} 101216262829$ & 61308 & $21 \mid 441$ & $0.96(0.32$ to 2.84$)$ & 0.94 & 0 & 0.50 \\
\hline Inflammation 816 & 3159 & 22172 & $0.22(0.00$ to 12.07$)$ & 0.46 & 84 & $0.01^{*}$ \\
\hline Discharge $^{8916}$ & $8 \mid 123$ & $17 \mid 135$ & $0.66(0.14$ to 3.23$)$ & 0.61 & 58 & 0.09 \\
\hline Necrosis ${ }^{15} 16$ & 1192 & 3197 & $0.51(0.07$ to 3.88$)$ & 0.52 & 0 & 0.43 \\
\hline Allergic reaction 91526 & $2 \mid 226$ & $1 \mid 211$ & $1.37(0.22,8.60)$ & 0.74 & 0 & 0.59 \\
\hline Abscess $^{1029}$ & $2 \mid 115$ & 21244 & $\begin{array}{l}1.86(0.22 \text { to } 15.71) \\
\text { Mean difference }(95 \% \mathrm{Cl})\end{array}$ & 0.57 & 0 & 0.37 \\
\hline Closure time $^{1728}(\mathrm{~min})$ & \multicolumn{2}{|c|}{ Sutures vs staples } & $5.84(4.52$ to 7.15$)$ & $<0.001$ & 0 & $0.55^{\star}$ \\
\hline
\end{tabular}

Primary and secondary outcomes comparing sutures to staples for skin closure after orthopaedic surgery. All outcomes (95\% $\mathrm{Cl})$ are calculated using the Mental-Haeszel random-effects model. Heterogeneity is calculated using the $\mathrm{I}^{2}$ statistic. $\chi^{2}$ significance level dictates whether the heterogeneity between studies is significant $\left({ }^{*} p<0.05\right)$. 


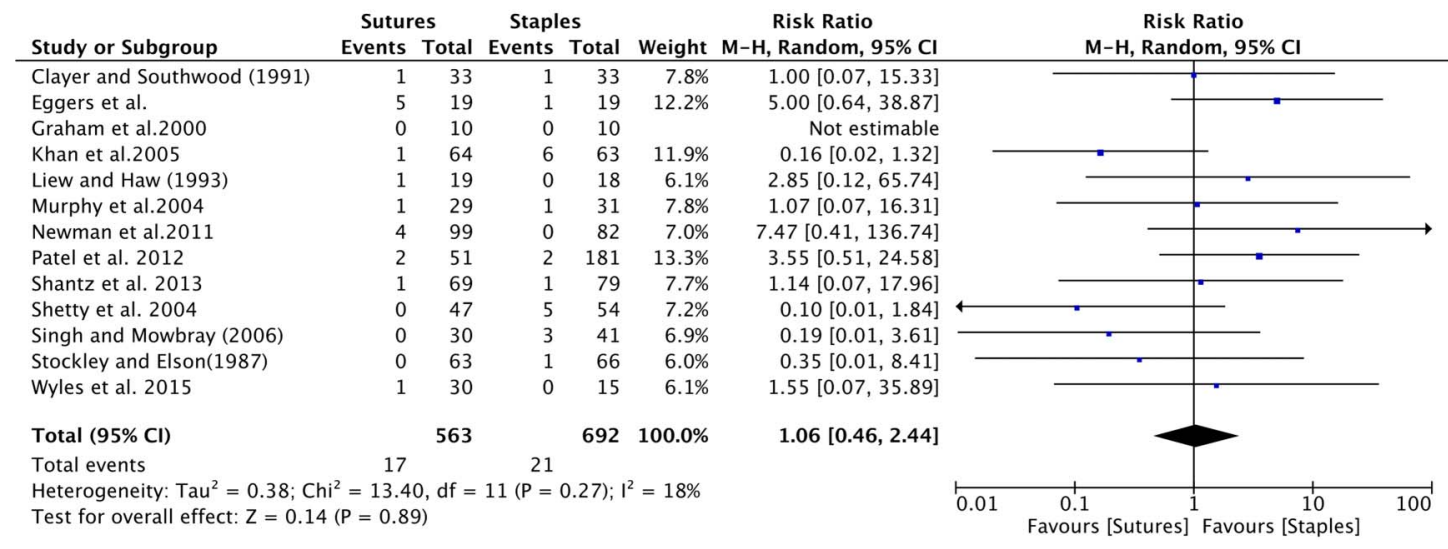

Figure 2 Forest plot of the cumulative risk ratio $(95 \% \mathrm{Cl})$ of wound infection comparing patients who received staples or sutures for wound closure after orthopaedic surgery. Analysis conducted with Mantel-Haenzel random-effects model.

IQR and thus, could not be used for the cumulative effect estimate.

5. Length of stay: Two studies reported LOS. ${ }^{92}$ However, Eggers $e t a l^{28}$ and Khan $e t$ a ${ }^{9}$ reported LOS as mean (CI) and median (IQR) days, respectively. Normality was not assumed, and the data was not combined. Qualitatively, there is no noticeable difference among patients who receive staples or sutures.

6. HRQoL: Only one study administered the Short Form-36, a generic HRQoL questionnaire within suture and staple groups. ${ }^{28}$ There was no difference in HRQoL across all subscales.

\section{Sensitivity analysis}

Three randomised controlled trials reported results as per protocol. We adjusted the results according to ITT and performed a sensitivity analysis to examine the overall RR of infection. Accounting for lost to follow-up, the RR of infection remained insignificant (table 5, figures 4 and 5).

\section{Subgroup analysis}

1. Hip surgery: Six studies provided data comparing infection between patients receiving sutures to staples after hip surgery. ${ }^{8-10} 121529$ The cumulative sample size was 164 and 245 patients in the suture and staple group, respectively. The cumulative risk ratio was insignificant, with a RR of 0.48 ( 0.10 to 2.45 ; figure 6$)$.
2. Knee surgery: Seven studies provided data comparing infection between patients receiving sutures to staples after knee surgery. ${ }^{9} 15$ 25-29 The cumulative sample size was 239 and 263 patients in the suture and staple group, respectively. The cumulative risk ratio was insignificant, with a RR of 1.38 (0.42 to 4.52; figure 7).

\section{Publication bias}

Publication bias was assessed using a funnel plot for our primary outcome of infection (figure 8). The funnel for studies was not fully symmetrical. Included studies were scattered throughout the bottom and top right corner of the plot. Yet, there seems to be some evidence for missing studies as seen by the empty space in the top left corner. Nevertheless, publication bias can be suspected but cannot be concluded based on this plot. The reason for difficulty in interpretation is mainly due to the small group of studies and high heterogeneity and small effect size. In addition, publication bias can be one of many possible explanations for our funnel plot asymmetry.

\section{DISCUSSION}

As compared with the systematic review and meta-analysis published in $2009,{ }^{7}$ we found no significant difference in infection among patients who receive staples and sutures for skin closure. Although there was no significant

\begin{tabular}{|c|c|c|c|c|c|}
\hline \multirow[b]{2}{*}{ Study or Subgroup } & \multicolumn{2}{|c|}{ Sutures } & \multicolumn{2}{|c|}{ Staples } & \multirow[b]{2}{*}{ Weight $I$} \\
\hline & Events & Total & Events & Total & \\
\hline Clayer and Southwood (1991) & 0 & 33 & 1 & 33 & $11.8 \%$ \\
\hline Eggers et al. 2011 & 1 & 19 & 2 & 19 & $22.1 \%$ \\
\hline Murphy et al.2004 & 1 & 29 & 1 & 31 & $15.9 \%$ \\
\hline Newman et al.2011 & 3 & 99 & 0 & 82 & $13.6 \%$ \\
\hline Patel et al. 2012 & 1 & 51 & 0 & 181 & $11.7 \%$ \\
\hline Shetty et al. 2004 & 0 & 47 & 1 & 54 & $11.7 \%$ \\
\hline Singh and Mowbray (2006) & 0 & 30 & 2 & 41 & $13.1 \%$ \\
\hline Total $(95 \% \mathrm{Cl})$ & & 308 & & 441 & $100.0 \%$ \\
\hline Total events & 6 & & 7 & & \\
\hline Heterogeneity: $\operatorname{Tau}^{2}=0.00$; & 5.37 & $\mathrm{dr}=6$ & $=0$. & ); $1^{2}=$ & $\%$ \\
\hline
\end{tabular}

Risk Ratio Risk Ratio $0.33[0.01,7.90]$ $0.50[0.05,5.06]$ $1.07[0.07,16.31]$ $5.81[0.30,110.88]$ $10.50[0.43,253.94]$ $0.38[0.02,9.16]$ $0.27[0.01,5.45]$ $0.96[0.32,2.84]$

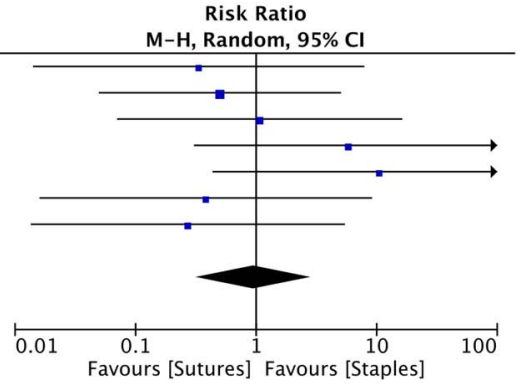

Figure 3 Forest plot of the cumulative risk ratio $(95 \% \mathrm{Cl})$ of wound dehiscence comparing patients who received staples or sutures for wound closure after orthopaedic surgery. Analysis conducted with Mantel-Haenszel random effects model. 


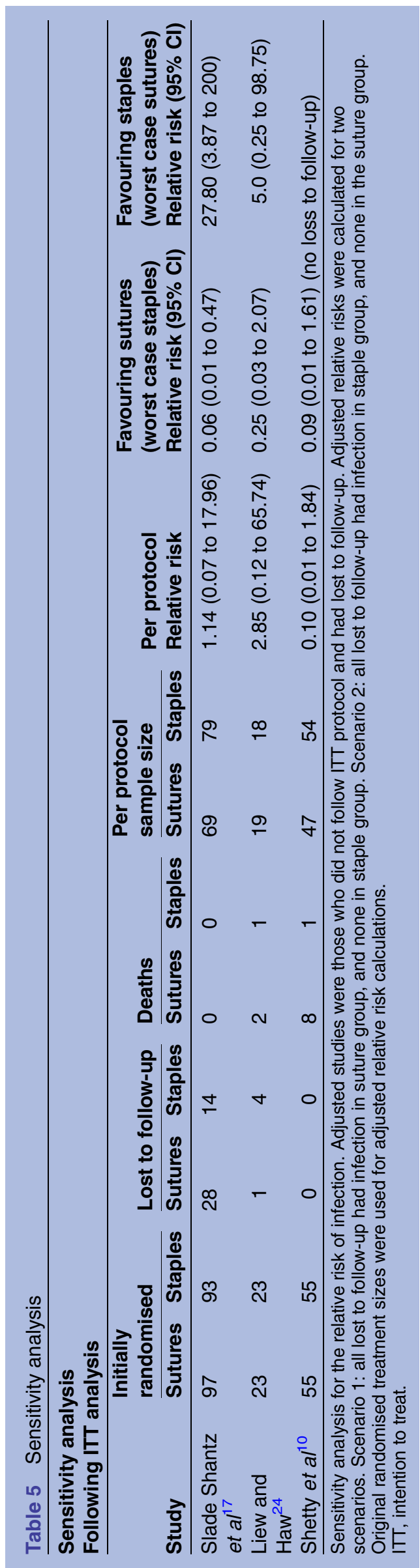

heterogeneity across all studies ( $p>0.05)$, there was some noticeable variation in magnitude and direction of effect (figure 1). In addition, our study also showed no significant difference in dehiscence, inflammation, discharge, necrosis, allergic reaction, and abscess formation. Three studies did not report results as per ITT. Sensitivity analysis was conducted following ITT analysis. Two scenarios were created accounting for two logical extreme cases. Scenario 1 assumes all lost to follow-up within the suture group had infection, and patients who received staples developed no infection. Conversely, scenario 2 assumes all patients who were lost to follow-up within the staple cohort received infection and no patient experienced infection in the suture group. The risk of infection comparing sutures to staples within scenarios 1 and 2 was insignificant, further strengthening our conclusion of no significant difference in infection risk between sutures and staples. However, it is important to note that the magnitude of effect was large within both scenarios (figures 4 and 5; table 5), suggesting that our sensitivity analysis may have been underpowered to detect a significant difference.

Subgroup analysis was also performed comparing the effect of sutures and staples on infection, stratified by surgery type. Limitations on available data allowed us to only analyse the effect of infection comparing hip and knee surgery only. There was no significant difference in the incidence of infection across both surgery types. In hip surgery, the results suggested a potential protective effect of the use of sutures against infection. The heterogeneity across studies was insignificant and the majority of studies favoured staples for skin closure (figure 6). The insignificant, large magnitude of effect suggests that our study may have been underpowered to detect a significant difference. Nevertheless, our result lends support to the conclusions by Smith $e t a l^{7}$ in which they reported patients who undergo hip surgery and receive staples may have a higher risk for developing postoperative infection. In contrary, within knee surgery, there was considerable variation in direction of effect across both groups (figure 7). The use of sutures was potentially harmful, with a RR of 1.38 (0.42 to 4.52). However, caution must be given to the interpretation of results in this particular group due to the significant heterogeneity in magnitude and direction of effect between studies. With respect to patient-centred outcomes, only two studies measured patient-reported pain. ${ }^{15}{ }^{17}$ Unfortunately, the results from both studies could not be combined quantitatively. However, based on qualitative analysis, there seems to be trend that staples cause more pain on removal than sutures. This trend is consistent with non-orthopaedic surgeries. ${ }^{30-32}$

Given that there may be no significant difference in the use of staples or sutures for skin closure, potential logistic and economic implications should also considered. Within our study, four articles measured closure time. ${ }^{9} 1724{ }^{28}$ However, only two studies could be quantitatively synthesised. ${ }^{17} 28$ The MD of closure time (min) 


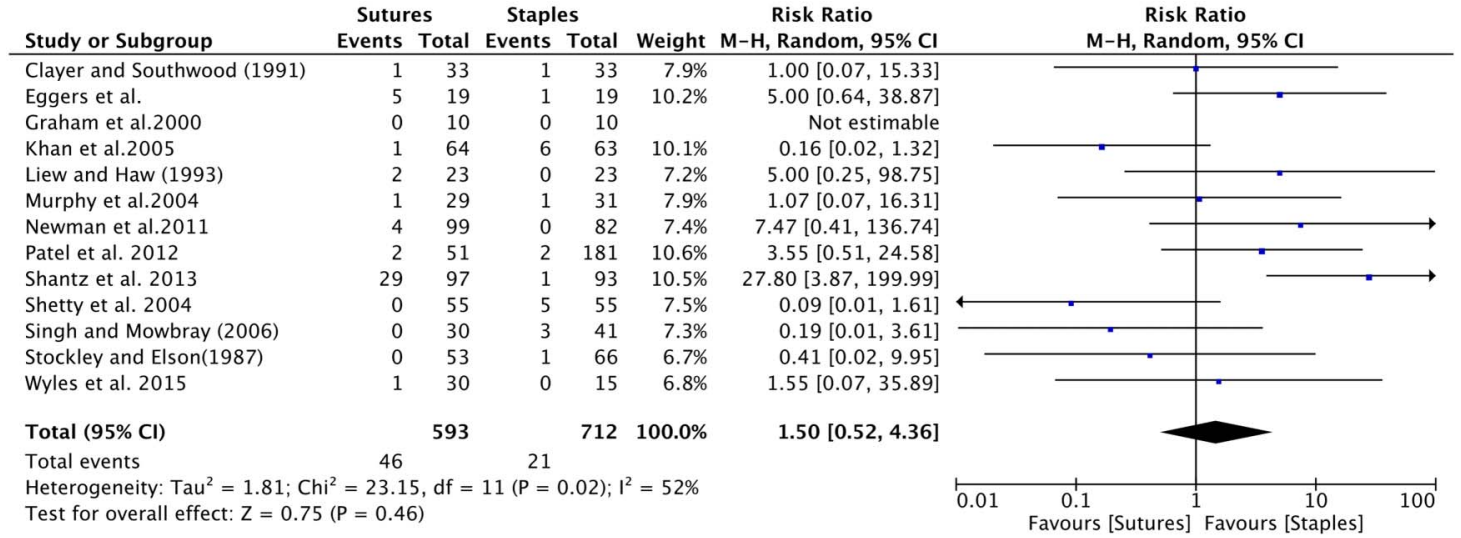

Figure 4 Forest plot indicating the adjusted relative risk (RR; 95\% Cl) of infection within scenario 1: all lost to follow-up had infection in the suture group, thus favouring staples. Original randomised treatment sizes were used for RR calculations. Cumulative effect was calculated using the Mantel-Haenzel random-effects model.

comparing sutures to staples was 5.84 (4.52 to 7.15). The results do suggest that staples may be slightly faster to use compared with sutures for skin closure. Slade Shantz et $a l^{17}$ reported an estimated 7 min time savings with the use of staples for skin closure. If an average orthopaedic surgeon were to perform five surgeries per day, the use of staples could save an estimated $35 \mathrm{~min}$ of operative time potentially reducing overscheduling and hospital costs. ${ }^{17} 28$ Liew and $\mathrm{Haw}^{24}$ also noted that the use of staples for skin closure was approximately 7 times faster as compared with sutures. However, the potential utility of staples for skin closure may still be a false economy driven by surgeon perception and bias. ${ }^{7}$ The use of staples has always been noted as a "more expensive method' for skin closure as compared with using sutures. ${ }^{15} 16$ In addition, the number dressing changes required for patients who undergo skin stapling is much higher than those who undergo suturing. ${ }^{7}$ Consequently, the savings in intraoperative costs could be negated by costs in dressing changes and staple/ applicator costs. To our knowledge, no formal costbenefit analysis has been done comparing the use of sutures and staples for orthopaedic surgery. Other economical considerations include difference in LOS comparing sutures to staples. A shorter LOS can result in shorter postoperative costs, inpatient care, physical therapy and pharmaceuticals. ${ }^{28}$ Additionally, Eggers et $a l^{28}$ noted that the level of wound cosmesis might also affect LOS, such that a shorter LOS may be partly due to a higher emotional satisfaction predicated on a more cosmetically appealing incision.

In our study, there seems to be no noticeable difference in LOS comparing sutures to staples. However, it is important to note that only two studies analysed LOS, and our conclusions are solely speculative.

A major limitation of our SRMA is the substantially low quality of evidence and considerable heterogeneity across studies. Of the 13 studies included, 7 studies did not provide baseline characteristics. ${ }^{10} 151624-2629$ Thus, we could not conclusively establish that patients between groups were similar across all confounders for infection such as age, body mass index and comorbidity burden. ${ }^{7}$

Another potential limitation is that we included two studies in which comparing wound complications

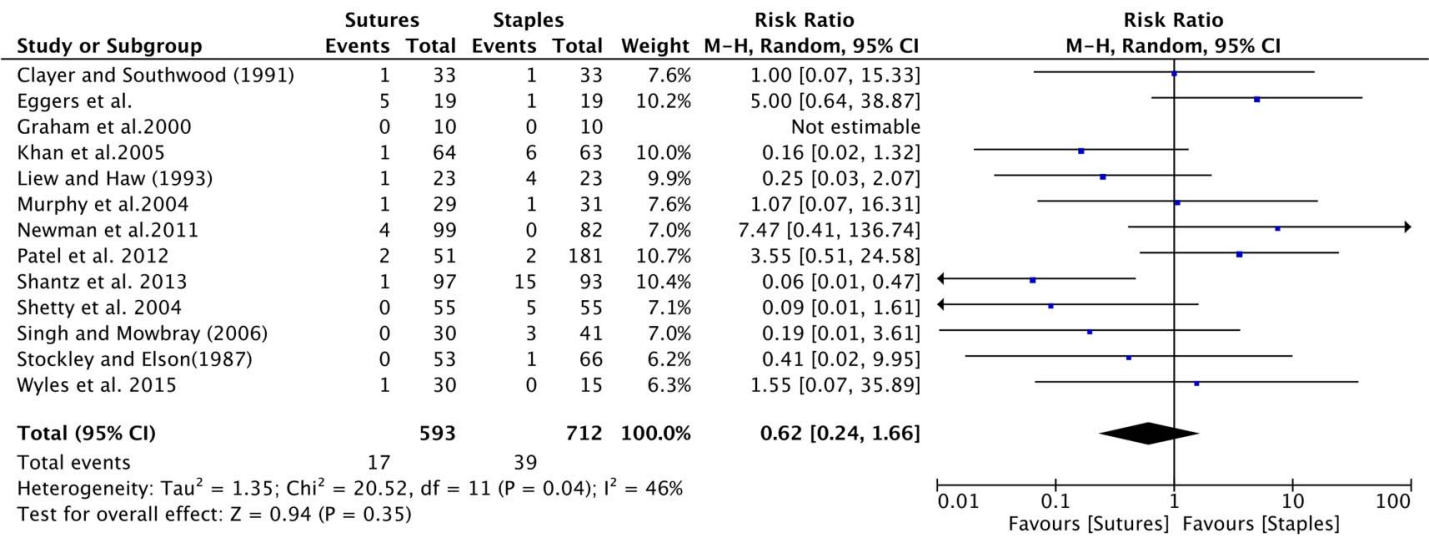

Figure 5 Forest plot indicating the adjusted relative risk (RR; 95\% Cl) of infection within scenario 2: all lost to follow-up had infection in the staple group, thus favouring sutures. Original randomised treatment sizes were used for RR calculations. Cumulative effect was calculated using the Mantel-Haenzel random-effects model. 


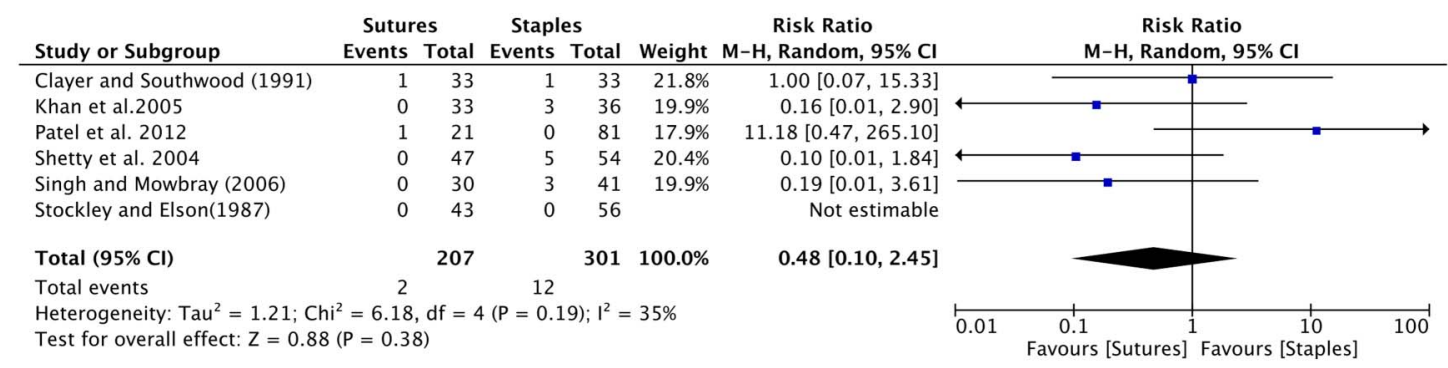

Figure 6 Forest plot indicating relative risk $(95 \% \mathrm{Cl})$ within hip surgeries. Cumulative effect was calculated using the Mantel-Haenzel random-effects model.

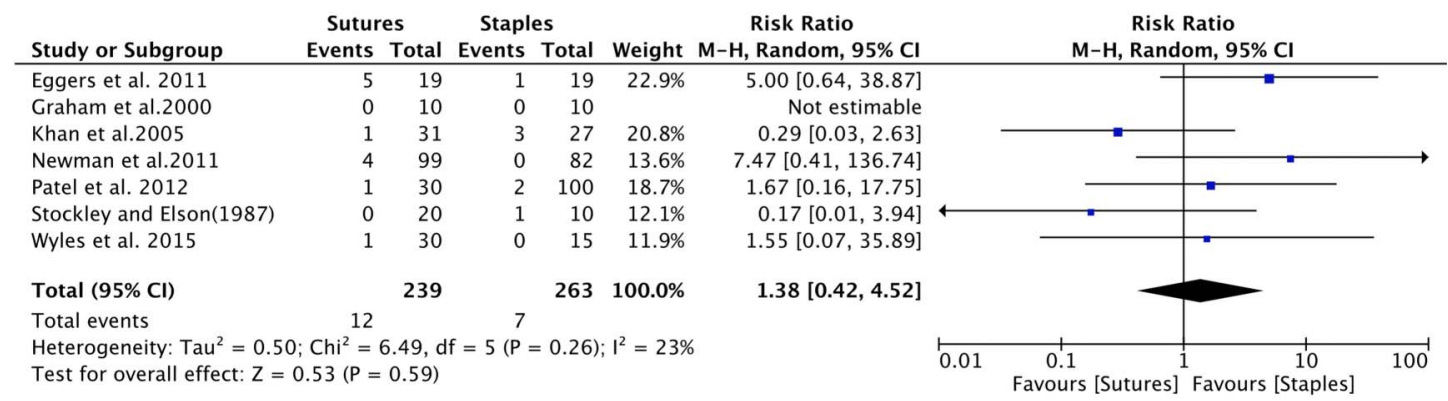

Figure 7 Forest plot indicating relative risk $(95 \% \mathrm{Cl})$ within knee surgeries. Cumulative effect was calculated using the Mantel-Haenzel random-effects model.

between sutures and staples was not the primary objective. ${ }^{25} 27$ One study which was published in the year 2000 was captured by the previous systematic review/ meta-analysis. ${ }^{7}$ The authors noted that the study was excluded because comparing the incidence of wound complications was not the primary objective. However, for the purposes of our SRMA, the two studies were included because they effectively randomised patients to suture and staple treatments. In addition, information on postoperative infection was reported within both studies.

In addition, no information was available evaluating specific suture techniques, or surgeon skill. Murphy et $a l^{16}$ suggested that poor surgical technique and accuracy of suture or staple closure can have an effect

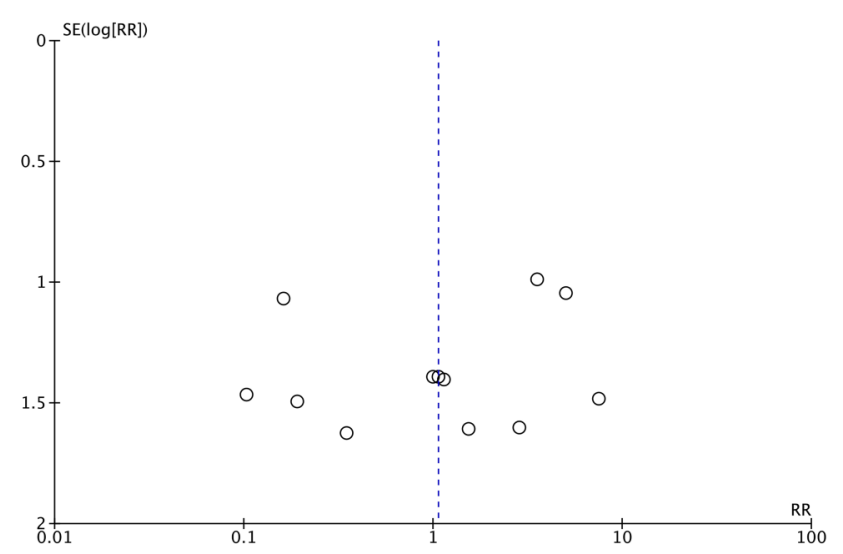

Figure 8 Funnel plot examining potential publication bias for incidence of wound infection after orthopaedic surgery (RR, relative risk). on wound healing. However, it is unclear whether suturing technique is confounder with respect to postoperative wound complications. ${ }^{7}$ Second, the majority of studies did not specify whether infections were superficial or deep. Superficial infections typically require the administration of antibiotics while deep infections require more severe courses of treatment. ${ }^{7}$

The strengths of our study are twofold. First, our SRMA was completed with high methodological rigour. All of our outcomes and subgroup analysis were prespecified and our study was registered with PROSPERO prior to data extraction. Second, in contrast to Smith et $a l^{7}{ }^{7}$ we found no significant difference comparing sutures to staples across all post-operative complications and subgroups; suggesting that there may be no clinically relevant difference in effect between the two skin closure methods within this population.

Future studies should focus on conducting highquality randomised control trials. Detailed baseline characteristics, and a detailed patient recruitment flow chart should be presented. In addition, authors should remove themselves from 'as per protocol' analysis and convey results according to the ITT principle. Second, our study failed to capture two large randomised controlled trials because they had not yet been completed. Thus, future SRMAs should be conducted comparing the use of sutures to staples for skin closure.

Acknowledgements The authors would like to thank Mr John Costella for his dedication and guidance. Without his help, this project would not be possible.

Contributors All authors had made impactful contributions to the manuscript submitted. RK is the primary author of said manuscript. He made substantial contributions to the design of the work, acquisition of data, analysis/ 
interpretation, and writing the manuscript. SDM played an integral role in selecting included studies during the screening process. She provided necessary guidance, support and mentorship throughout the whole process. She was involved in study design, statistical analysis and revising intellectual property. MSM-M played an integral role for this study. She provided necessary guidance, support and mentorship throughout the whole process. She was involved in study design, statistical analysis and revising the intellectual property.

Funding This research received no specific grant from any funding agency in the public, commercial or not-for-profit sectors.

Competing interests None declared.

Provenance and peer review Not commissioned; externally peer reviewed.

Data sharing statement No additional data are available.

Open Access This is an Open Access article distributed in accordance with the Creative Commons Attribution Non Commercial (CC BY-NC 4.0) license, which permits others to distribute, remix, adapt, build upon this work noncommercially, and license their derivative works on different terms, provided the original work is properly cited and the use is non-commercial. See: http:// creativecommons.org/licenses/by-nc/4.0/

\section{REFERENCES}

1. Mangram AJ, Horan TC, Pearson ML, et al. Guideline for prevention of surgical site infection, 1999. Hospital Infection Control Practices Advisory Committee. Infect Control Hosp Epidemiol 1999;20:250-78; quiz 279-80.

2. Li G, Guo F, Ou Y, et al. Epidemiology and outcomes of surgical site infections following orthopedic surgery. Am J Infect Control 2013;41:1268-71

3. Saadatian-Elahi M, Teyssou R, Vanhems P. Staphylococcus aureus, the major pathogen in orthopaedic and cardiac surgical site infections: a literature review. Int $J$ Surg 2008;6:238-45.

4. Whitehouse JD, Friedman ND, Kirkland KB, et al. The impact of surgical-site infections following orthopedic surgery at a community hospital and a university hospital: adverse quality of life, excess length of stay, and extra cost. Infect Control Hosp Epidemiol 2002;23:183-9.

5. Bachoura A, Guitton TG, Smith RM, et al. Infirmity and injury complexity are risk factors for surgical-site infection after operative fracture care. Clin Orthop Relat Res 2011;469:2621-30.

6. Owens CD, Stoessel K. Surgical site infections: epidemiology, microbiology and prevention. J Hosp Infect 2008;70(Suppl 2):3-10.

7. Smith TO, Sexton D, Mann C, et al. Sutures versus staples for skin closure in orthopaedic surgery: meta-analysis. BMJ 2010;340: c1199.

8. Singh B, Mowbray MAS, Nunn G, et al. Closure of hip wound, clips or subcuticular sutures: does it make a difference? Eur J Orthop Surg Traumatol 2006;16:124-9.

9. Khan RJ, Fick D, Yao F, et al. A comparison of three methods of wound closure following arthroplasty: a prospective, randomised, controlled trial. J Bone Joint Surg Br 2006;88:238-42.

10. Shetty AA, Kumar VS, Morgan-Hough C, et al. Comparing wound complication rates following closure of hip wounds with metallic skin staples or subcuticular vicryl suture: a prospective randomised trial. $J$ Orthop Surg (Hong Kong) 2004;12:191-3.

11. Livesey C, Wylde V, Descamps S, et al. Skin closure after total hip replacement: a randomised controlled trial of skin adhesive versus surgical staples. J Bone Joint Surg Br 2009;91:725-9.
12. Clayer M, Southwood RT. Comparative study of skin closure in hip surgery. Aust N Z J Surg 1991;61:363-5.

13. Eldrup J, Wied U, Andersen B. Randomised trial comparing proximate stapler with conventional skin closure. Acta Chir Scand 1981;147:501-2.

14. Chughtai $T$, Chen $L Q$, Salasidis $G$, et al. Clips versus suture technique: is there a difference? Can J Cardiol 2000;16:1403-7.

15. Stockley I, Elson RA. Skin closure using staples and nylon sutures: a comparison of results. Ann R Coll Surg Engl 1987;69:76-8.

16. Murphy M, Prendergast P, Rice J. Comparison of clips versus sutures in orthopaedic wound closure. Eur J Orthop Surg Traumatol 2004:14:16-18.

17. Slade Shantz JA, Vernon J, Morshed S, et al. Sutures versus staples for wound closure in orthopaedic surgery: a pilot randomized controlled trial. Patient Saf Surg 2013;7:6.

18. Moher D, Liberati A, Tetzlaff J, et al. PRISMA-P Group. Preferred reporting items for systematic reviews and meta-analyses: the PRISMA statement. BMJ 2009;339:b2535.

19. Guyatt GH, Oxman AD, Sultan S, et al. GRADE guidelines: 9. Rating up the quality of evidence. J Clin Epidemiol 2011;64:1311-16.

20. Guyatt GH, Oxman AD, Kunz R, et al. GRADE guidelines: 8. Rating the quality of evidence-indirectness. J Clin Epidemiol 2011;64:1303-10.

21. Guyatt GH, Oxman AD, Kunz R, et al. GRADE guidelines: 7. Rating the quality of evidence--inconsistency. J Clin Epidemiol 2011;64:1294-302.

22. Guyatt GH, Oxman AD, Kunz R, et al. GRADE guidelines 6. Rating the quality of evidence-imprecision. J Clin Epidemiol 2011;64:1283-93.

23. Review Manager (RevMan) [Computer program]. Version 5.3. Copenhagen: The Nordic Cochrane Centre, The Cochrane Collaboration, 2014.

24. Liew SM, Haw CS. The use of taped skin closure in orthopaedic wounds. Aust N Z J Surg 1993;63:131-3.

25. Graham D, Jeffery J, Bain D, et al. Staple vs. subcuticular vicryl skin closure in knee replacement surgery: a spectrophotographic assessment of wound characteristics. Knee 2000;7:239-43.

26. Newman JT, Morgan SJ, Resende GV, et al. Modality of wound closure after total knee replacement: are staples as safe as sutures? A retrospective study of 181 patients. Patient Saf Surg 2011;5:26.

27. Wyles CC, Jacobson SR, Houdek MT, et al. The Chitranjan Ranawat award: running subcuticular closure enables the most robust perfusion after TKA: a randomized clinical trial. Clin Orthop Relat Res 2016;474:47-56.

28. Eggers MD, Fang L, Lionberger DR. A comparison of wound closure techniques for total knee arthroplasty. J Arthroplasty 2011;26:1251-8.e1-4.

29. Patel RM, Cayo M, Patel A, et al. Wound complications in joint arthroplasty: comparing traditional and modern methods of skin closure. Orthopedics 2012;35:e641-6.

30. Frishman GN, Schwartz T, Hogan JW. Closure of Pfannenstiel skin incisions. Staples vs. subcuticular suture. J Reprod Med 1997:42:627-30.

31. Reed MR, Lennard TW. Prospective randomized trial of clips versus subcuticular polydioxanone for neck wound closure. Br J Surg 1997;84:118.

32. Selvadurai D, Wildin C, Treharne G, et al. Randomised trial of subcuticular suture versus metal clips for wound closure after thyroid and parathyroid surgery. Ann R Coll Surg Engl 1997;79:303-6.

33. Moher D, Liberati A, Tetzlaff J, et al. The PRISMA Group. Preferred reporting items for systematic reviews and meta-analyses: the PRISMA statement. PLoS Med 2009;6:e1000097. 